\title{
The Promotion of Intercultural Communicative Competence in Current International Trade
}

\author{
XU Xuhong ${ }^{1}$, CAI Lanlan ${ }^{2} *$ \\ ${ }^{1}$ Business School of Quanzhou Normal University, Quanzhou 362000, Fujian, China \\ 2,* School of Foreign Languages, Quanzhou Normal University, Quanzhou 362000, Fujian, China \\ cllan2004@163.com
}

Keywords: international trade; intercultural communication; business negotiation

\begin{abstract}
With the advance of globalization and the popularization of network technology, the international political, economic and cultural exchanges increased, and at the same time, between different countries people's business activities and political exchanges also encounter obstacles, so the importance of intercultural communication is highlighted gradually. Intercultural communication ability includes such aspects as psychology, emotion, behavior and cognition, and short-term cross-cultural training is difficult to complete. Therefore, it is very important to discuss the countermeasures to improve intercultural communication competence in international trade. This paper mainly studies the influence and development trend of intercultural communication competence on international trade, and then probes into the countermeasures for improving intercultural communicative competence in international trade.
\end{abstract}

\section{Introduction}

After entering twenty-first century, the global space limitation has been broken, the political, economic and cultural factors between countries communicate with and even penetrate each other, multinational corporations, multinational corporations, international trade and other trade patterns flourish like bamboo shoots after a spring rain, and at the same time, trade competition has become increasingly fierce. Enterprises should base themselves on the fierce international trade, in addition to highlighting their own competitive advantages, and in the meanwhile, they should constantly improve cross-cultural communicative competence and overcome barriers in communicating with other countries.

\section{The influence of intercultural communicative competence on international trade}

As global openness increases, business communication between people is becoming more and more frequent. In international trade, however, with the main background and culture differences, negotiation process often fail owing to different cultural backgrounds, so the competence of the international trade depends largely on the intercultural communicative competence between the main trades.

\section{The impact on international market development}

In recent years, more and more enterprises begin to open up overseas markets, and establish overseas branches, and to open foreign markets and communicate with the local people and transactions, it is necessary to understand the local customs and habits. And customs in different countries are different, so in the market, if not in accordance with the local conditions and the actual situation, it is very easy to make the company a loss phenomenon in blindly operating according to domestic procedures and rules and regulations and other operating companies. For example, in women's clothing investment, if in the United States and Europe, the clothes can be bright, open the 
appropriate, while in Arabia, for the status of women is low, whose dressing is more conservative, the clothing colors and styles must be paied attention to.

\section{The impact on international trade cooperation}

Influence of intercultural communication is firstly reflected in language communication, many business activities carried out in languages, and different languages, idioms have obvious differences. These language habits cannot be formed overnight--- the foundation of trade between the two sides is first language communication, and second language habits. As in the west in the personnel and title, Chinese use surname and given name together in business talks, while the United States, Britain and other Indo European countries, the trade members in the first greeting use "Miss" and "Mr"before the name. The influence of intercultural communication is secondly reflected in behavior, people in every country since childhood education influenced by the family environment and cultural background, so there is a huge difference in the behavior. For instance, when talking business on the table, the French are used to talking business after the dinner, while the Germans are accustomed to the business before the meal, and Chinese are mostly talking business at the table. The influence of intercultural communication is revealed in the last movement, in which each country says hello and introduces each other in different ways. To a simple greeting, different countries have hundreds of forms, such as Chinese habit of shaking hands, Japanese habit of bowing, and a simple handshake also has big differences, such as the American habit of a firm handshake to express kindness, while the British think a soft handshake as a gentleman's performance.

\section{The impact on multinational companies management model}

Due to cultural differences, habits, values and beliefs of different people's mode of thinking, habits have obvious differences, and therefore, the enterprise must be in accordance with the custom of the local people to develop the company system in creation of multinational companies, and the establishment of the company operation mode etc.. For example, westerners possess the more sophisticated calculation ability in economy, used to work within the company's time, life and work without interference, and overtime will be more repulsive, while our employees are more likely to adapt to overtime work. Therefore, in the operation of transnational corporations, the company leadership must fully understand the local people's living habits, and formulate the management approach that all staff can comply with, so that employees feel respected. In the past, multinational corporations had "headquarters" mentality, and they believed that after their success in China, the experience and management methods could be implemented all over the world, but ignored the local cultural traditions. Many multinational companies used to expatriate managers to participate in the mode of foreign branch management, but the actual effect was poor. In recent years, more and more multinational companies have paied attention to this problem, and begun to change the employment mode, engaging managers from the local recruit the talents, and the effect is significant.

\section{The Future Trends of Intercultural Communication}

\section{Diversified cross-cultural communication}

With the integration and collision of cultures, new ideas and cultures collide with each other. New cultures are springing up, and modern civilization is developing rapidly, making intercultural communication more and more diversified. First of all, transnational corporations are still the main position and favorable environment for cross-cultural communication. In the future, more and more multinational companies will inevitably emerge, which will effectively promote the exchange and integration of cultures. Cross cultural communication form is diversified. The late Qing Dynasty seclusion in China stood behind the western countries, and the powers of aggression, in view of the lessons of the new Chinese after the establishment of people's government implemented a series of reform measures, such as the reform and opening up and joining the WTO series of countries, achieve a comprehensive cultural and political exchanges with other countries the economy. Since 
twenty-first Century, intercultural communication has become increasingly frequent, and the forms have become more and more diverse. The number of foreign students studying abroad and the number of foreign scholars who have been studying in China have increased significantly. Promoting cross-cultural communication is largely due to the development of network technology, and with the development and further open form of science and technology, the international trade can be carried out through the internet phone and video phone, breaking through the face-to-face talks form, thus effectively saving the meeting time, convenient to both parties.

\section{More extensive cross-cultural communication}

The intercultural communication is mainly used in international trade and business cooperation. With the development of economy, international trade is further deepened, and the scope of intercultural communication is also more and more extensive, involving political, academic exchanges and medical help etc.. Each country's cultural background and history are different with its own significance, and it is the product of human civilization. It is of great significance to study the laws of human development and social changes. Continuing to promote the process of socialization, the world increases significantly in the academic exchanges, and worldwide exchange students are more frequent. The exchange students'going abroad to study and exchange cultures was the state government behavior, but with the improvement of people's economic level, more and more people are beginning to participate in the study abroad, so the development scope of intercultural communication is significantly widened. The medical community between the exchanges has gradually increased in recent years, and more and more countries, hospitals, doctors begin to communicate frequently, so the world's top medical treatment technology can rapidly popularized and benefit mankind, and the traditional Chinese medicine in China has thousands of years of history, broad and profound, gradually exudes a unique charm and also, attracts more and more foreign scholars to learn.

\section{More deep cross-cultural communication}

Due to the channel, policy, and other aspects of the constraint language, intercultural communication in international society of people is still at a shallow level, failing to achieve universal communicative situation, and however, as the development of intercultural communication continuously enriches the contents, the improvement of people's economic level between countries will become increasingly close, and become a common way of the folk exchange. People from other countries can be more deeply exposed to different countries' culture, language, habits and so on.

\section{Countermeasures to improve intercultural communicative competence in international trade}

\section{Change the attitude and face the differences between cultures}

With the advance of reform and opening process and the impact of globalization, foreign thoughts have great influence on people's life, so we should double positive view of things, not exclude the differences between different cultures. The positive part of culture should be absorbed and reasonably applied to economic construction, national construction and other aspects of education. On the other hand, for some bad cultures, such as money worship, hatred of communism and individualism, should be understood with peace of mind, and the government departments ought to do a good job of supervision and guidance, so as to realize the intercultural communication. With attitude, knowledge and contact analysis ability, discovery and communication and cultural awareness of the critical ability, as well as the mutual understanding among ethnic customs and culture, can avoid misunderstanding in business and the conflict. In cross-cultural communication, we must take the essence and reject the dross. 


\section{Publicize traditional culture and strengthen the foundation of national culture}

In recent years, more and more young people have been in fond of Valentine's day, Christmas and so on, but for our traditional culture, such as the Dragon Boat Festival, the Double Ninth Festival, etc. are ignored. Although people's living standards have improved, however, compared with the past, the traditional Spring Festival, Mid Autumn Festival and other festivals lack the atmosphere and flavor. Foreign dietary culture also has a deeper impact on young people. McDonald's, Starbucks and other foreign dishes and foreign drinks have caused great impacts on Chinese food and tea. More and more parents send their children to bilingual kindergarten, educational institutions to study, but ignore the inheritance of traditional culture, leading to the less and less cognition of traditional culture among youngsters, so the state government must do the guidance, vigorously promote national culture, and enhance the people's sense of national pride, so that the fine traditions of the Chinese nation and folk customs can be preserved and extended to the whole world. In recent years, the idioms competition and poetry competition held by CCTV have not only won the praise of the domestic audience, but also absorbed a large number of audiences abroad. It has proved the charm of our national culture.

\section{Foster global awareness and respect cultural differences}

In order to achieve the smooth expansion of trade activities, it is necessary to have global awareness and respect for cultural differences among different ethnic groups. China culture and people, and in the final analysis between international trade exchanges also need full exchange and cooperation among the two bodies, and if the harmony among people cannot be reached, even the superior investment environment and the hardware cannot achieve the desired effect of cooperation. The United States and Germany's Daimler Lelaisile company, for example, began to merge and gained worldwide recognition, but after the merger the economic efficiency of enterprises did not rise but fell because the two sides eventually had management philosophy differences and cultural differences. International trade will inevitably lead to the collision and fusion of cultural differences and trade-offs. In trade, only treating their own culture as the center, but ignoring the other national partners and cultural values will inevitably lead to the bankruptcy of international trade.

\section{Enhance cultural sensitivity and promote foreign culture learning}

People are accustomed to using their own thinking patterns and fixed cultural atmosphere in thinking, which is also an important reason for the formation of different cultural values. With the development of intercultural communication, on the one hand, learners are required to input their existing knowledge and cultural exchange equivalent conditions, and on the other hand they are required unconditional positive understanding, sensitive to absorb different cultures. There are two main aspects of intercultural sensitivity: flexibility and openness. The former refers to the people to change the cultural scene back in accordance with the specific adjustment of the behavior, while the latter refers to others willing to accept different ideas. In order to improve the ability of intercultural communication in international trade, countries must encourage people to learn cultural diversity, in addition to learning a foreign language as well as the culture and national consciousness of different countries by watching movies, reading literary works, communicate with foreigners and a variety of other ways to be actively connected with foreigners, more skilled and accurate in dealing with the problems caused by the cross-cultural communication.

\section{Conclusion}

With the increase of global business activity, intercultural communication has become an inevitable trend, and gradually penetrate into other fields, which will have a huge impact on the trade and commerce and people's life. In order to improve the ability of cross-cultural communication and deal with the global cultural exchange, we must accept critically the western culture with an open mind, carry forward the national culture, improve the ability of learning foreign culture, and thus takes the initiative in the process of globalization to realize the national rejuvenation and win the superior position in international trade. 


\section{Acknowledgements}

Project supported by Fujian Natural Science Foundation of China: Research on e-commerce chain based on Collaborative vision in cloud computing environment (2015J01286).

Project entrusted by Quanzhou Development and Reform Commission: Five special studies on socialism in Quanzhou (2017).

\section{References}

[1] Yue Wen Jun. From the perspective of cross culture marketing on the cultivation of intercultural communicative competence of [J]. China high-tech enterprises, 2009 (2): 54-55.

[2] Bai Yuan. Study on the cultivation mode of international business students' intercultural business ability [J]. higher education research, Chengdu, 2012 (2): 77-81.

[3] Xu Wei. The cultivation of intercultural communicative competence in Business English teaching from the perspective of Chinese and Western tea culture [J]. Fujian tea, 2017 (9): 224-225.

[4] Gao Shuna, Zheng Mingxin, Li Rongjian. Journal of cross culture from the perspective of code switching and business negotiation of [J]. in Jilin Province Institute of education management, 2013 (11): 131-133.

[5] Tan Shengfeng, the white Zhiwu. Application of cross cultural comparison method in the history of science and technology -- about [J]. Journal of Guangxi University for Nationalities from Joseph Needham "China ancient history of scientific thought" (NATURAL SCIENCE EDITION), 2001 (3): $197-200$.

[6] Ji Jia Jing. The policy of trade protection under the economic crisis -- to "buy American BuyAmerican" as an example of [J]. Chinese Economic Herald, 2009 (15).

[7] Zhang Lihua. Research on the social mechanism of cross cultural communication in the context of comprehensive reform of international trade taking Yiwu city as an example [J]. Journal of Hubei University of Economics (HUMANITIES AND SOCIAL SCIENCES), 2012, 9 (7): 117-119.

[8] Zhu Chunfei. Research on intercultural communicative competence based on the narrative of practice scenarios. Taking international trade majors in Higher Vocational Colleges as an example [J]. Journal of Mudanjiang University, 2013 (9): 158-160. 